\title{
AVALIAÇÃO TÉCNICA E ECONÔMICA DA COLHEITA FLORESTAL COM FELLER-BUNCHER
}

\author{
Amanda Coimbra Nascimento ${ }^{1}$, Ângelo Márcio Pinto Leite² Thelma Shirlen Soares $^{3}$, Luis Carlos de Freitas ${ }^{4}$
}

(recebido: 10 de outubro de 2009; aceito: 27 de setembro de 2010)

\begin{abstract}
RESUMO: O Feller-buncher constitui uma das máquinas mais utilizadas na colheita florestal, cuja principal função é realizar a derrubada e o enleiramento das árvores. Objetivou-se, neste trabalho, avaliar técnica e economicamente a derrubada de árvores inteiras com o Feller-buncher, em duas posições distintas de tombamento destas, em florestas de eucalipto (posição 1 = derrubada a $45^{\circ}$ e, posição $2=$ derrubada a $90^{\circ}$ ). A análise técnica englobou um estudo de tempos e movimentos e de produtividade. A análise econômica contemplou os parâmetros custo operacional, custo de produção e rendimento energético. Concluiu-se que não houve diferença entre as posições 1 e 2 de derrubada quanto ao tempo para realizar o tombamento das árvores, tendo sido o corte o elemento parcial que consumiu a maior parte do tempo do ciclo operacional, com aproximadamente $66 \%$ deste, nas duas posições de derrubada. A produtividade por hora efetiva de trabalho do Feller-buncher foi de, aproximadamente, 347 árvores (48,8 m³/he), o custo operacional de $\mathrm{R} \$ 195,26$, proporcionando um custo de produção da máquina de $\mathrm{R} \$ 3,95 / \mathrm{m}^{3}$ e um rendimento energético de 3,8 g/W m³ , para ambas as posições de derrubada das árvores. Apesar da similaridade em termos de produtividade e custo das duas posições de derrubada avaliadas, recomenda-se tombar as árvores à $45^{\circ}$, devido à maior facilidade de enleiramento destas, bem como no intuito de beneficiar a operação subsequente (extração).
\end{abstract}

Palavras-chave: Mecanização florestal, produtividade, custo de produção.

\section{TECHNICAL AND ECONOMICAL ANALYSIS OF THE FOREST HARVESTING WITH FELLER-BUNCHER}

\begin{abstract}
The Feller-buncher is a machine used in for forest harvesting, whose main function is to cut and gather trees. In this study, we performed a technical and economical analysis of felling whole trees with the Feller-buncher in two different areas of eucalyptus stands (position 1 = cut to 45th and position 2 = cut to 90th). The technical analysis included a study of times and movements and of productivity. The economical analysis evaluated the parameters of operational cost, production cost, and energy income. Positions 1 and 2 did not differ with regard to tipping, as to the time to complete the registration of the trees and was cutting the partial element that consumed most of the operational cycle time, with approximately $66 \%$ of this, the two positions dropped. The productivity per effective hour of work of the Feller-buncher was approximately 347 trees $\left(48.8 \mathrm{~m}^{3} / \mathrm{he}\right)$, the operating cost of $R \$ 195.26$, giving a production cost of the machine from $R \$ 3.95 \mathrm{per} \mathrm{m}^{3}$ and an efficiency of $3.8 \mathrm{~g} / \mathrm{W} \mathrm{m}$ for both positions of felled trees. Despite the similarity in terms of productivity and cost of the two positions evaluated, we recommend cutting trees down to 45 th, due to ease of overturning these and to facilitate subsequent operations (extraction).
\end{abstract}

Key words: Forest mechanization, productivity, production cost.

\section{INTRODUÇÃO}

Inserida em um contexto global que afeta sobremaneira a rentabilidade das empresas, a mecanização da atividade de colheita florestal passa por momentos de grandes inovações e avanços tecnológicos. Entretanto, o setor ressente-se ainda da falta de dados confiáveis para a escolha do sistema e da máquina mais adequada, tanto economicamente, quanto tecnicamente.
Para Arce et al. (2004), a colheita florestal representa a operação final de um ciclo de produção florestal, na qual são obtidos os produtos mais valiosos, constituindo um dos fatores que determinam a rentabilidade florestal.

Basicamente, as atividades da colheita podem ser divididas em três fases: corte (incluindo a derrubada, o desgalhamento e o processamento), extração (que corresponde à colocação da madeira em um local de fácil acesso) e transporte para o local de utilização, sendo que o

\footnotetext{
${ }^{1}$ Engenheira Florestal - Departamento de Engenharia Florestal - Universidade Federal dos Vales do Jequitinhonha e Mucuri - Rua da Glória, 187 39.100-000 - Diamantina, MG - amandacoimbramalaka@yahoo.com.br

${ }^{2}$ Engenheiro Florestal, Professor Dr. em Ciência Florestal - Departamento de Engenharia Florestal - Universidade Federal dos Vales do Jequitinhonha e Mucuri - Rua da Glória, 187 - 39.100-000 - Diamantina, MG - ampleite@ig.com.br

${ }^{3}$ Engenheira Florestal, Professora Dra. em Ciência Florestal - Universidade Federal de Goiás - Campus Jataí - Cx. P. 3 - $75801-615$ - Jataí, GO thelma.soares@hotmail.com

${ }^{4}$ Engenheiro Florestal, Professor Dr. em Ciência Florestal - Departamento de Fitotecnia e Zootecnia - Universidade Estadual do Sudoeste da Bahia Estrada do Bem Querer, Km 04 - Cx. P. 95 - 45.083-900 - Vitoria da Conquista, BA - luiscarlos_ufv@yahoo.com.br
}

Cerne, Lavras, v. 17, n. 1, p. 9-15, jan./mar. 2011 
desafio dos técnicos florestais é otimizar todas as operações envolvidas (MALINOVSKI et al., 2008), uma vez que diversas máquinas, equipamentos, métodos e sistemas são utilizados.

De acordo com Lima e Leite (2008), os principais tratores utilizados na colheita florestal são: o Harvester (colhedor e processador), o Feller-buncher (derrubador acumulador), o Slingshot e a Garra traçadora (processador e/ou traçador), o Forwarder (trator transportador), o Skidder (trator arrastador) e o Carregador florestal (trator equipado com grua hidráulica).

Atualmente, as empresas empregam uma variada linha de maquinários e equipamentos na colheita de madeira, em virtude da quantidade de marcas e modelos existentes para a realização das operações de corte e extração florestal, cabendo a cada uma optar por aquele sistema/método que seja mais adequado às suas peculiaridades.

O Feller-buncher constitui uma das máquinas mais utilizadas na colheita florestal, cuja principal função é realizar a derrubada e o enleiramento das árvores (JACOVINE et al., 1997). O corte de derrubada é realizado concomitantemente à sustentação e acumulação de árvores no cabeçote, normalmente por um disco rotativo serrilhado, constituindo-se o conjunto ativo responsável pelo corte dos fustes por acionamento hidráulico. As árvores cortadas são sustentadas e acumuladas por meio de um conjunto de braços de acionamento hidráulico, que as recolhe inteiras. Com o braço acumulador, a árvore cortada é presa ao cabeçote para então se cortarem outras árvores até que a capacidade máxima de carga seja atingida (entre três e sete árvores, conforme o diâmetro e massa específica dessas), efetuando assim, a chamada derrubada direcionada.

No desenvolvimento de sistemas de colheita de madeira, Seixas et al. (2004) consideram o estudo de tempos e movimentos uma técnica de suma importância, uma vez que o tempo consumido para cada um dos elementos do ciclo de trabalho permite a organização do trabalho, com os objetivos de otimizar o sistema operacional com o mínimo de tempos improdutivos; deduzir a produtividade e o custo por unidade produzida em relação a certos fatores relevantes; e, em combinações com medidas ergonômicas, estabelecer o esforço humano requerido para cada uma das atividades.

Segundo Rezende et al. (1997), a melhoria da qualidade, a racionalização dos processos e a minimização de custos são itens de suma importância para um melhor desempenho da atividade de colheita e, portanto, vital para qualquer empresa florestal.

Entretanto, pesquisas relacionadas à avaliação da relação entre tempos e movimentos de tratores derrubadores - acumuladores em operações de colheita florestal e o número de árvores abatidas são escassos no Brasil, principalmente quanto à direção da derrubada em relação à linha de plantio. Objetivou-se, neste estudo, avaliar técnica e economicamente o corte com o Fellerbuncher, em duas posições de tombamento de árvores, em florestas de eucalipto.

\section{MATERIAL E MÉTODOS}

\subsection{Local de estudo}

Conduziu-se, este estudo, em povoamentos florestais de Eucalyptus sp., situados em Itamarandiba MG, região do Alto Jequitinhonha. O solo predominante na região é o Latossolo Vermelho - Amarelo de textura argilosa, com predominância de relevo plano, caracterizado por chapadas. A temperatura média é de $20,1^{\circ} \mathrm{C}$, sendo a máxima no verão de $26,1^{\circ} \mathrm{C}$ e a mínima no inverno de $15^{\circ} \mathrm{C}$, com clima seco e com baixa umidade relativa do ar e precipitação pluviométrica de $1.120 \mathrm{~mm}$ por ano, mal distribuído.

\subsection{Características técnicas do Feller-buncher e procedimento de corte}

O Feller-buncher avaliado é uma máquina de porte variável conforme a potência do motor, composto por uma escavadora de acionamento hidráulico com esteiras, podendo atingir até $200 \mathrm{KN}$, com velocidade de deslocamento oscilando entre $2,0 \mathrm{~km} / \mathrm{h}$ e $4,5 \mathrm{~km} / \mathrm{h}$. As principais características técnicas da máquina avaliada encontram-se na Tabela 1.

O procedimento de corte desta máquina consiste na fixação da árvore pelos dois braços à altura do dap (diâmetro medido a 1,3 metros de altura do solo) e, em seguida, no corte um pouco acima do nível do solo, com um disco de corte rotativo serrilhado. Após o corte da primeira árvore, os braços acumuladores são acionados, segurando os fustes na mesa acumuladora e reabrindo os braços principais para uma nova operação até completar a capacidade máxima de carga do equipamento (cabeçote). As árvores são, então, tombadas (descarregadas), formando feixes. Assim, as principais funções do Feller-buncher são executar o corte de derrubada, acumular e deslocar-se com as árvores em pé no seu cabeçote, depositando-as em um local sobre a área de corte. 
Tabela 1 - Características técnicas do Feller-buncher avaliado.

Table 1-Technical characteristics of the Feller-buncher evaluated.

\begin{tabular}{lc}
\hline \multicolumn{3}{c}{ Máquina base } \\
\hline Marca & Carterpillar \\
Modelo & $320 \mathrm{CL}$ \\
Fabricação & 2006 \\
Potência Nominal & $103 \mathrm{KW}$ \\
\hline \multicolumn{2}{c}{ Cabeçote de corte } \\
\hline \multicolumn{2}{c}{ Modelo Capacidade de abastecimento } \\
Capacidade de corte & 16 \\
Peso & $400 \mathrm{~L}$ \\
Número de bits & $19,5 \mathrm{KN}$ \\
\hline \multicolumn{2}{c}{ Can L } \\
\hline Tanque de combustível & $120 \mathrm{~L}$ \\
Sistema Hidráulico & $30 \mathrm{~L}$ \\
Reservatório do Hidráulico \\
Carter do motor \\
\hline \multicolumn{2}{c}{ Ruído } \\
\hline
\end{tabular}

Fonte: Manual técnico da máquina.

\subsection{Descrição dos subsistemas de colheita avaliados}

O sistema de colheita florestal empregado é o de árvores inteiras, sendo a madeira extraída após a derrubada para a beira da estrada e processada com comprimento entre 2,3 a 3,0 metros, em função do tamanho do forno de carbonização.

A faixa ou eito de corte adotada pela empresa é de cinco linhas, em que a máquina trafega em direção à terceira linha efetuando seu corte, realizando em seguida o corte da primeira e segunda linha de um lado (esquerdo) e, o da quarta e quinta linha do outro (direito).

O Feller-buncher inicia a derrubada com cinco linhas de corte, direcionando a base dos feixes das árvores de acordo com a direção da extração, uma vez que metade da madeira é arrastada para um lado do talhão e a outra metade, para o lado oposto da extremidade desse, de acordo com a distância preestabelecida para o deslocamento do Skidder. Após realizar o corte das cinco árvores, o Fellerbuncher as derruba formando feixes de madeira a $45^{\circ}$ na posição 1 ou a $90^{\circ}$ em relação ao alinhamento de plantio na posição 2, conforme Figura 1.

O Feller-buncher retorna em direção à terceira linha para começar um novo ciclo, na segunda linha de plantio. A etapa subsequente é a extração com o Skidder, o qual se desloca da margem da estrada até próximo do local onde se encontram os feixes e os arrasta para a margem do talhão. A última etapa do sistema consiste no traçamento dos fustes em toras na margem do talhão, realizado pela garra traçadora, que se posiciona a mais ou menos dois metros dos feixes arrastados pelo skidder, iniciando o processamento pela base desses. a)

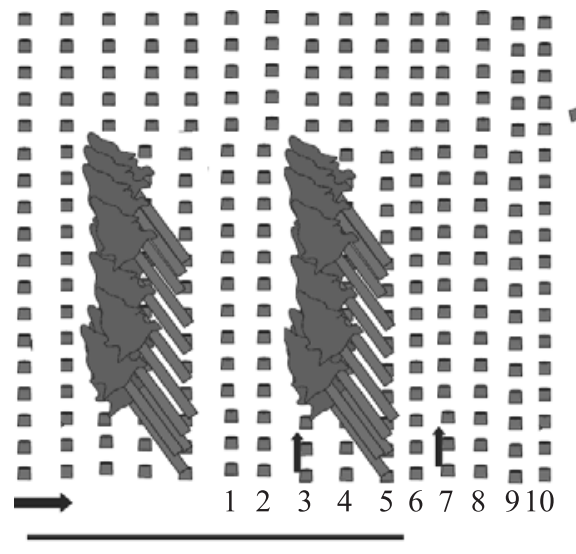

Estrada

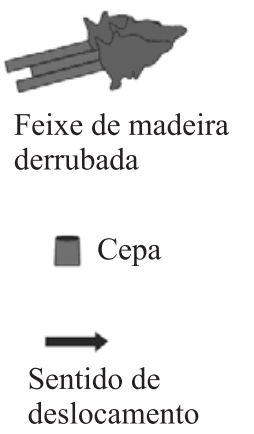

b)

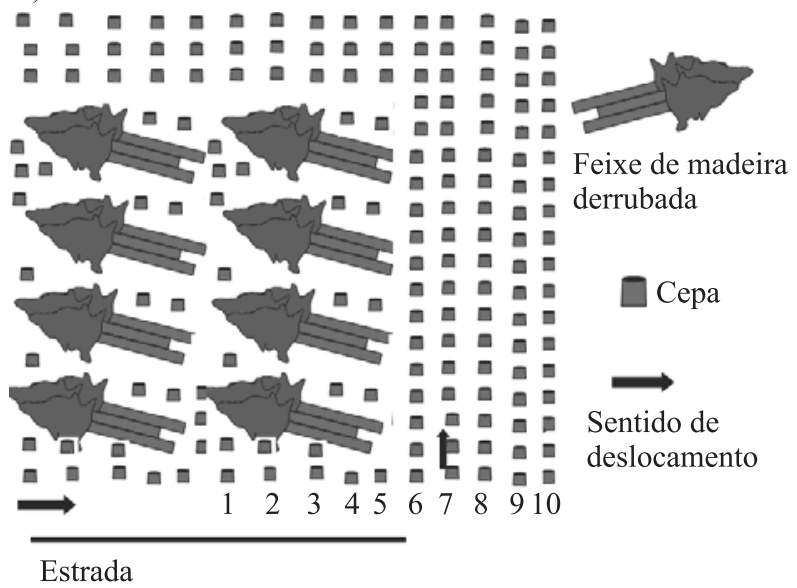

Figura 1 - a) Posição 1= corte formando ângulo de $45^{\circ}$ com a linha de plantio; b) Posição 2 = corte formando ângulo de $90^{\circ}$ com a linha de plantio.

Figure 1 - a) Position 1 = cut to form 45-degree angle with the line of planting b) Position 2 = cut to form 90-degree angle with the line of planting. 


\subsection{Coleta de dados}

Inicialmente, realizou-se um estudo piloto das posições de tombamento analisadas para a definição do número de observações necessárias, a fim de proporcionar um erro de amostragem máximo de 5\% em um nível de 95\% de probabilidade, segundo metodologia proposta por Barnes (1999):

$n \geq \frac{t^{2}+C V^{2}}{E^{2}}$

em que:

n = número mínimo de ciclos necessários;

$\mathrm{t}$ = nível de probabilidade desejado a (n-1) graus de liberdade;

$\mathrm{CV}=$ coeficiente de variação, em porcentagem; e

$\mathrm{E}=$ erro admissível, em porcentagem.

Considerando-se o número de observações necessárias e as faixas de corte normalmente utilizadas pela empresa, definiu-se o tamanho mínimo da área a ser colhida para cada posição de tombamento, que proporcionasse o número mínimo de observações coletadas. A partir de então, selecionou-se um talhão onde foram alocadas duas parcelas de 50 faixas de plantio cada, sendo uma derrubada a $45^{\circ}$ e a outra, a $90^{\circ}$ (graus), com relação à linha de plantio. Com o inventário pré-corte da área total (23,12 ha) e o censo de cada parcela, foi possível levantar as características dendrométricas das parcelas (Tabela 2).

\subsection{Análise técnica}

Para o estudo de tempo e movimentos dos ciclos operacionais do Feller-buncher foram coletados dados dos elementos parciais de um ciclo completo de operação da máquina.

Os elementos parciais foram o deslocamento vazio (que ocorria com a procura de árvores para o abate), o corte (que se iniciava com o apoio do cabeçote ao chão e terminava com o corte da última árvore e o abraçamento da mesma), o deslocamento para o descarregamento (que ocorria logo após o corte e finalizava-se com o depósito das árvores no chão) e as interrupções (se classificaram em interrupções mecânicas e em dificuldades operacionais que ocorriam durante o processamento, por motivos diversos).

Para avaliar o efeito de todas as operações no ciclo das atividades desenvolvidas pelo Feller-buncher nas duas posições analisadas durante a colheita florestal, na produtividade 195,26 $\mathrm{m}^{3} /$ ha foi empregado o delineamento estatístico em blocos casualizados, adotando-se os ângulos de derrubada das árvores efetuados em relação à linha de plantio como tratamentos. Os tempos observados foram submetidos à análise de variância e ao teste de Tukey, a $5 \%$ de probabilidade.

\subsection{Análise econômica}

A análise econômica baseou-se nos seguintes parâmetros:

a) Determinação do custo operacional da máquina: foi determinado pelo método contábil, com valores estimados em reais. Esse englobou o somatório dos custos fixos (depreciação, juros e seguros) e custos variáveis (combustível, lubrificantes e graxa, óleo hidráulico, pneus/ esteiras, manutenção e reparo, transporte de maquinário, pessoal operacional e administrativo).

No cálculo do custo operacional do Feller-buncher, considerou-se apenas a porção do tempo total durante o qual essa máquina foi programada para executar um trabalho produtivo, conforme mencionado por Lopes et al. (2008, 2009), utilizando-se dados de sua eficiência operacional cedido pela empresa, proveniente de uma série histórica mais completa, obtidos mensalmente.

b) Custo de produção: obtido pela divisão dos custos operacionais pela produtividade da máquina:

$\mathrm{CPr}=\frac{\mathrm{CT}}{\text { Prod }}$

em que:

$\mathrm{CPr}=$ custo de produção da máquina analisada $\left(\mathrm{R} \$ / \mathrm{m}^{3}\right)$;

$\mathrm{CT}$ = custo operacional total da máquina analisada (R\$/he); Prod $=$ produtividade da máquina analisada $\left(\mathrm{m}^{3} / \mathrm{he}\right)$.

Tabela 2 - Características dendrométricas das árvores das parcelas.

Table 2 - Tree dendrometric characteristics of plots.

\begin{tabular}{cccccc}
\hline Área (ha) & DAP médio $(\mathrm{cm})$ & Altura média $(\mathrm{m})$ & Volume $\left(\mathrm{m}^{3} / \mathrm{ha}\right)$ & № árvores/ha & № de arvores $/ \mathrm{m}^{3}$ \\
\hline 5,7 & 13,96 & 18,47 & 195,26 & 1388 & 7,11 \\
6,0 & 13,96 & 18,47 & 196,38 & 1396 & 7,11 \\
\hline
\end{tabular}

Cerne, Lavras, v. 17, n. 1, p. 9-15, jan./mar. 2011 
c) Rendimento energético (RE): obtido pela razão entre o consumo específico de combustível (g/kW h) e a produtividade do Feller-buncher $\left(\mathrm{m}^{3} / \mathrm{he}\right)$ :

$$
\mathrm{RE}=\frac{\mathrm{Ce}}{\text { Prod }}
$$

em que:

$\mathrm{RE}=$ rendimento energético da máquina analisada (g/ $\mathrm{kW} \mathrm{cc}$ );

Ce = consumo específico de combustível da máquina analisada (g/kW h);

Prod $=$ produtividade da máquina analisada $\left(\mathrm{m}^{3} / \mathrm{he}\right)$.

\section{RESULTADOS E DISCUSSÃO}

\subsection{Estudo de tempos e movimentos}

Os tempos totais para as duas posições avaliadas foram submetidos à análise de variância pelo teste F, a 5\% de probabilidade, apresentando valores não significativos (Tabela 3).

Tabela 3 - Análise de variância dos valores de tempo gasto nas posições analisadas.

Table 3 - Analysis of variance of the time spent in analyzed positions.

\begin{tabular}{lcccc}
\hline Fonte da variação & G.L & QM & F & P(\%) \\
\hline Blocos & 8 & 8,4395 & & \\
Subsistemas & 1 & 30,212 & 1,1355 & 0,3176 \\
Resíduo & 8 & 26,605 & & \\
Total & 17 & & & \\
\hline
\end{tabular}

Como não houve diferença significativa entre as duas posições de derrubada quanto ao tempo total gasto em um ciclo operacional completo do Feller-buncher, ambas as posições podem ser usadas, mas sugere-se a derrubada à $45^{\circ}$, devido à maior facilidade de tombamento das árvores pela máquina, bem como no intuito de favorecer a operação subsequente (extração). Fica claro assim que, os dois ângulos de corte $\left(45^{\circ}\right.$ e $\left.90^{\circ}\right)$, posições de tombamento 1 e 2 , respectivamente, tendem a apresentar custo operacional semelhante.

Pela Figura 2 mostra-se a distribuição média de tempos dos elementos do ciclo operacional do Fellerbuncher, nas posições 1 e 2 .

Estes valores correspondem a um ciclo operacional de corte, composto de 5 árvores, em média. O tempo de

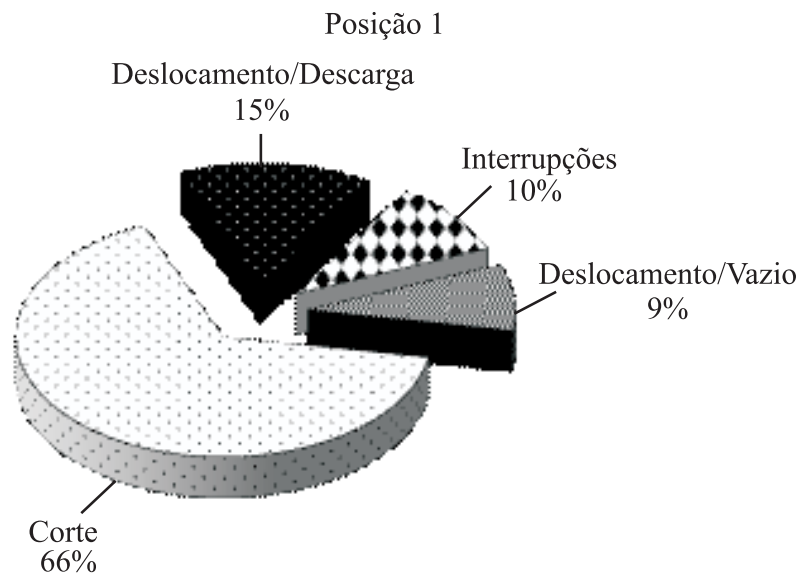

Posição 2

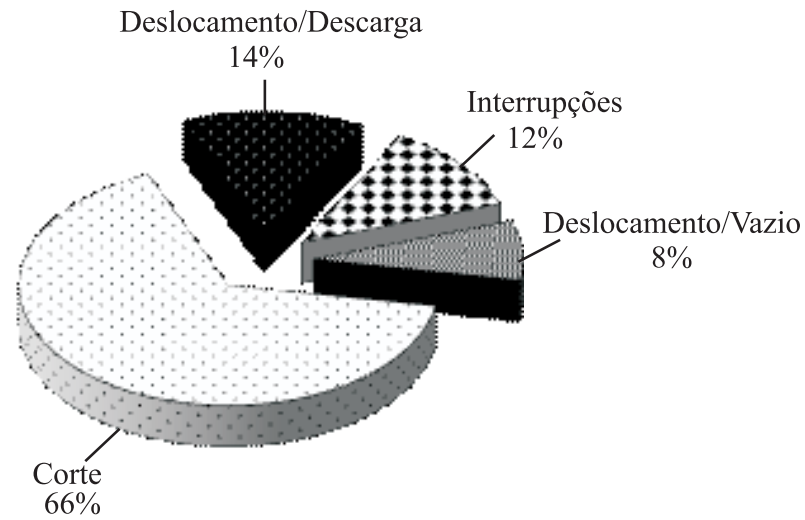

Figura 2 - Composição porcentual dos elementos do ciclo operacional do Feller-buncher, nas posições 1 e 2.

Figure 2 - Percentage breakdown of the elements of the operational cycle of the Feller-buncher, in positions 1 and 2.

corte corresponde ao tempo para realizar a busca e o corte, acumular as árvores no cabeçote de corte e o deslocamento desse em busca de outras árvores.

Conforme a Figura 2, o elemento parcial que consumiu a maior parte do tempo total do ciclo operacional foi o corte, com $66 \%$ nas duas posições. Em seguida, veio o deslocamento para o descarregamento com 15 e $14 \%$ do tempo total do ciclo e as interrupções com 10 e $12 \%$, nas posições 1 e 2, respectivamente.

As principais interrupções operacionais verificadas foram: apanhar árvores que escapavam no processo de acúmulo no cabeçote, rebaixar cepa, eliminar subbosque, arranjar feixe quando essas árvores ficavam mal organizadas e realizar o deslocamento.

Cerne, Lavras, v. 17, n. 1, p. 9-15, jan./mar. 2011 
O elemento deslocamento vazio foi o que consumiu menor tempo, com 9 e $8 \%$ do tempo total do ciclo, nas posições 1 e 2 respectivamente. Em média, o Fellerbuncher gastou 40,66 e 40,7 segundos para completar um ciclo total, nas posições de tombamento das árvores 1 e 2, respectivamente (Tabelas 4 e 5).

Tabela 4 - Média de tempo de cada elemento e tempo total, em segundos, gasto para realização do ciclo operacional na posição de tombamento 1 .

Table 4 - Average length of each element and total time, in seconds, spent in the operational cycle position tipping 1 .

\begin{tabular}{lc}
\hline Operações & Tempos (segundos) \\
\hline Corte & $26,77 \mathrm{a}$ \\
Deslocamento para descarga & $5,98 \mathrm{~b}$ \\
Interrupções & $4,13 \mathrm{c}$ \\
Deslocamento vazio & $3,78 \mathrm{c}$ \\
Tempo Total Médio & 40,66 \\
\hline
\end{tabular}

Médias seguidas das mesmas letras na coluna não diferem entre si $(\alpha=5 \%)$.

Tabela 5 - Média de tempo de cada elemento e tempo total, em segundos, gasto para realização do ciclo operacional na posição de tombamento 2 .

Table 5 - Average length of each element and total time, in seconds, spent in the operational cycle position tipping 2.

\begin{tabular}{lc}
\hline Operações & Tempos (segundos) \\
\hline Corte & $26,38 \mathrm{a}$ \\
Deslocamento para descarga & $5,90 \mathrm{~b}$ \\
Interrupções & $5,00 \mathrm{~b}$ \\
Deslocamento vazio & $3,78 \mathrm{c}$ \\
Tempo Total Médio & 41,06 \\
\hline
\end{tabular}

Médias seguidas das mesmas letras na coluna não diferem entre si $(\alpha=5 \%)$.

\subsection{Produtividade}

A produtividade média do Feller-buncher, por hora efetiva de trabalho, foi de 347 árvores, o que equivale a $48,8 \mathrm{~m}^{3} /$ he, nas duas posições de tombamento, tendo em vista não haver diferença no tempo de trabalho dessas.

\subsection{Custo operacional}

Considerando-se uma taxa de juros de $12 \%$ a.a. e uma eficiência operacional de 60,44\% (média do mês de janeiro), chegou-se ao custo hora, efetivamente trabalhada, de $\mathrm{R} \$ 192,36$.
Moreira et al. (2004), avaliando a atividade de corte em povoamentos de eucalipto de uma empresa do setor situados na região noroeste do estado de São Paulo, utilizando-se um Feller-buncher composto por uma escavadora de acionamento hidráulico com esteiras, marca Caterpillar, modelo $320 \mathrm{BL}$, obtiveram rendimento que variou de 33,47 a 36,10 m³/he, com custo operacional em torno de $\mathrm{R} \$ 171,34$, por hora efetiva. Esse custo mais baixo deve-se, provavelmente, a uma maior eficiência da máquina e às características inerentes à empresa em questão.

Os custos fixos corresponderam a aproximadamente $30,58 \%$ e os variáveis, a $67,35 \%$ dos custos totais, respectivamente. De todos os itens do custo operacional, a manutenção e reparos corresponderam ao maior porcentual (20,51\%), seguido do gasto com combustível (20,44\%) e depreciação $(17,04 \%)$. Por outro lado, o transporte de máquinas (1,94\%), administração (2,31\%), seguros (3,38\%) e gasto com esteira (3,46\%), corresponderam aos menores porcentuais do custo total, conforme Figura 3.

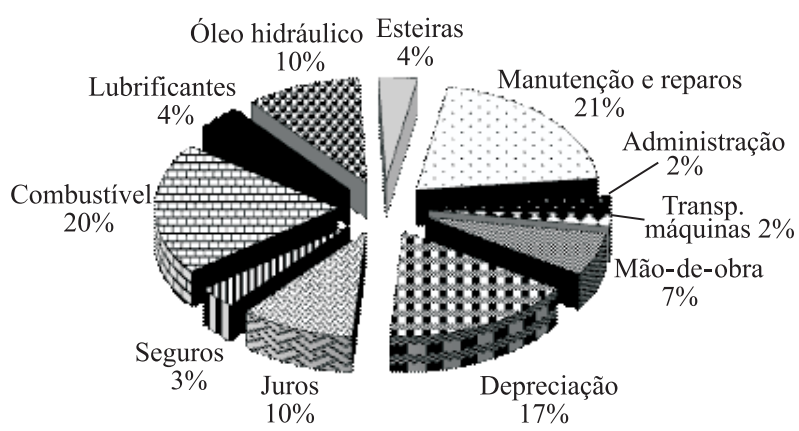

Figura 3 - Distribuição porcentual dos itens que compõem o custo operacional do Feller-buncher.

Figure 3 -Distribution of items that make up the operational cost of the Feller-buncher.

\subsection{Custo de produção e rendimento energético}

Considerando que o custo operacional, o consumo de combustível e a produtividade do Feller-buncher foram equivalentes para ambas as posições de tombamento das árvores, os valores de custo de produção e rendimento energético também foram semelhantes. Nesse sentido, o custo de produção verificado foi de $\mathrm{R} \$ 3,95 / \mathrm{m}^{3}$ para a produtividade de $195,26 \mathrm{~m}^{3} / \mathrm{ha}$, sem levar-se em consideração o custo de transporte do pessoal, que é terceirizado na empresa. O rendimento energético foi de 3,8 $\mathrm{g} / \mathrm{W} \mathrm{m}^{3}$, em função do consumo específico de combustível de 185,34 g/kW h. 


\section{CONCLUSÕES}

Na análise do ciclo operacional do Feller-buncher, verificou-se que não houve diferença entre as posições 1 e a 2, quanto ao tempo para realizar o tombamento das árvores, tendo sido o corte a operação que consumiu o maior tempo (correspondendo a $66 \%$ nas duas posições) e o menor tempo, o deslocamento vazio (9 e 8\% do tempo) nas posições 1 e 2 , respectivamente.

A produtividade por hora efetiva de trabalho do Feller-buncher foi de $48,8 \mathrm{~m}^{3}$, o custo operacional de $\mathrm{R} \$ 195,26$, proporcionando um custo de produção da máquina de $\mathrm{R} \$ 3,95 / \mathrm{m}^{3}$ e um rendimento energético de 3,8 g/W m³ , para ambas as posições de tombamento das árvores.

Apesar da similaridade, em termos de produtividade e custo das duas posições avaliadas, recomenda-se derrubar as árvores à $45^{\circ}$.

\section{AGRADECIMENTOS}

À ArcelorMittal BioEnergia, pela oportunidade de desenvolver este trabalho.

\section{REFERÊNCIAS}

ARCE, J. E.; MacDONAGH, P.; FRIEDL, R. A. Geração de padrões ótimos de corte através de algoritmos de traçamento aplicados a fustes individuais. Árvore, Viçosa, v. 28, n. 2, p. 383-391, 2004.

BARNES, R. M. Estudo de movimentos e de tempos: projeto e medida do trabalho. 6. ed. Rio de Janeiro: E. Blucher, 1999. 635 p.

JACOVINE, L. A. G.; MACHADO, C. C.; SILVA, M. L.; SOUZA, A. P. Evolução dos custos da madeira destinada à produção de celulose. In: SIMPOSIO BRASILEIRO SOBRE
COLHEITA E TRANSPORTE FLORESTAL, 3., 1997, Vitória. Anais... Viçosa, MG: SIF, 1997. p. 261-268.

LIMA, J. S. S.; LEITE, A. M. P. Mecanização. In: MACHADO, C. C. (Ed.). Colheita florestal. 2. ed. Viçosa, MG: UFV, 2008. p. 43-65.

LOPES, S. E.; FERNANDES, H. C.; MINETTE, L. J.; SILVEIRA, J. C. M.; RINALDI, P. C. N. Avaliação técnica e econômica de um "skidder" operando em diferentes produtividades e distâncias de extração. Ciência e Agrotecnologia, Lavras, v. 33, n. 6, p. 1621-1626, 2009.

LOPES, S. E.; FERNANDES, H. C.; SANTOS, N. T;; RINALDI, P. C. N. Avaliação técnica e econômica de uma garra traçadora operando em diferentes produtividades. Scientia Forestalis, Piracicaba, v. 36, n. 79, p. 215-222, 2008.

MALINOVSKI, R. A.; FENNER, P. T.; SCHACKKIRCHNER, H.; MALINOVSKI, J. R.; MALINOVSKI, R. A. Otimização da distância de extração de madeira com forwarder. Scientia Forestalis, Piracicaba, v. 36, n. 79, p. 171-179, 2008.

MOREIRA, F. M. T.; SOUZA, A. P.; MACHADO, C. C.; MINETTI, L. J.; SILVA, K. R. Avaliação operacional e econômica do "feller-buncher" em dois subsistemas de colheita de florestas de eucalipto. Árvore, Viçosa, v. 28, n. 2, p. 199-205, 2004.

REZENDE, J. L.; FIEDLER, N. C.; MELLO, J. M.; SOUZA, A. P. Análise técnica e de custos de métodos de colheita e transporte florestal. Lavras: UFLA, 1997. 50 p. (Boletim Agropecuário, 22).

SEIXAS, F.; BARBOSA, R. F.; RUMMER, R. Tecnologia protege saúde do operador. Revista da Madeira, São Paulo, v. 14, n. 82, p. 68-73, 2004 